\title{
Development of an ethanol combustion mechanism based on a hierarchical optimization approach
}

\author{
C. Olm ${ }^{* 1,2,3}$, T. Varga ${ }^{1,2}$, É. Valkó ${ }^{1,2}$, S. Hartl ${ }^{3}$, C. Hasse ${ }^{3}$, T. Turányi ${ }^{1}$ \\ ${ }^{1}$ Laboratory for Chemical Kinetics, Eötvös University (ELTE), Budapest, Hungary \\ ${ }^{2}$ MTA-ELTE Research Group on Complex Chemical Systems, Budapest, Hungary \\ ${ }^{3}$ Chair of Numerical Thermo-Fluid Dynamics, TU Bergakademie Freiberg, Freiberg, Germany
}

\begin{abstract}
A detailed multi-purpose reaction mechanism for ethanol combustion was developed for the use in high-fidelity numerical simulations describing ignition, flame propagation and species concentration profiles with high accuracy. Justified by prior analysis, an optimization of 44 Arrhenius parameters of 14 crucial elementary reactions using several thousand direct and indirect measurement data points was performed, starting from the ethanol combustion mechanism of Saxena and Williams (2007). The final optimized mechanism was compared to 13 reaction mechanisms frequently used in ethanol combustion with respect to their accuracy in reproducing the various types of experimental data.
\end{abstract}

\section{Introduction}

Ethanol is widely used as a renewable alternative fuel and gasoline additive. In the last decade, a considerable growth in the worldwide production of fuel ethanol was observed, with the United States being the most notable producer, followed by Brazil, the European Union and China [1]. While E10, E15 or other low-level blends are widely available in most industrialized countries nowadays, E85 (i.e. a fuel blend of $85 \% \mathrm{v} / \mathrm{v}$ ethanol and $15 \%$ $\mathrm{v} / \mathrm{v}$ gasoline) and pure ethanol gained importance only in recent years. In spite of the widespread use of ethanol in automotive engines, not all details of the chemistry related to ethanol combustion are fully understood. Describing the combustion kinetics of ethanol with higher accuracy has high scientific and practical significance, and can contribute to the development of more efficient car engines with lower pollutant emissions.

The aim of this work is to develop a robust and wellperforming detailed mechanism for ethanol combustion following a hierarchical mechanism optimization approach. This has two implications: First, the developed mechanism should be "backwards-compatible" and describe smaller combustion systems such as hydrogen and syngas accurately. Second, the optimization targets together with the reactions to be optimized shall be included in a step-by-step strategy, in increasing order of the number of reactions that are influential for the respective sub-group of optimization targets in each step. Thereby, the process of converging towards an optimal set of rate parameters can be accelerated.

\section{Collection of indirect experimental data}

A large amount of experimental work has been published on ethanol combustion (Table 1). Flame velocities were measured in spherical bombs [2-18], heat flux burners [19-27], using the counterflow twin-flame technique $[28,29]$ or a stagnation-point flat flame burner [30]. These literature data cover preheat temperatures of 298$500 \mathrm{~K}$, initial pressures of $0.9-13.8 \mathrm{~atm}$ and equivalence ratios of $\varphi=0.55-1.82$. Except for Nauclér and co-workers $[23,24]$, who carried out measurements in $\mathrm{Ar}$ and $\mathrm{CO}_{2}$ dilution with pure $\mathrm{O}_{2}$ oxidizer, all flame studies were carried out with (dry or wet) air.

Ignition delay times were measured in shock tubes, either using $\mathrm{Ar}$ and $\mathrm{Ne} / \mathrm{Ar}$ diluents [17, 31-35] $(\varphi=0.25$ 2 , conditions behind the reflected shock wave: $p_{5}=0.9$ $\left.16.9 \mathrm{~atm}, T_{5}=980-2222 \mathrm{~K}\right)$ or air [36-39] $(\varphi=0.3 / 1.0$, $\left.p_{5}=8.9-91.5 \mathrm{~atm}, T_{5}=778-1411 \mathrm{~K}\right)$ to dilute the fueloxygen mixture. Time-to-ignition data measured in a rapid compression machine (RCM) were published by [40] ( $\left.\varphi=0.3, T_{\mathrm{c}}=831-983 \mathrm{~K}, p_{\mathrm{c}}=10-50 \mathrm{bar}\right)$. Further measurements can also be found in literature [37].

In addition to flame velocity and ignition delay data, a large variety of concentration profiles were recorded in jet-stirred reactors [41, 42], flow reactors [43-46] and shock tubes $[17,47]$ various conditions $(\varphi=0.03-5, p=$ 1-12 atm, $T=760-1700 \mathrm{~K}$ ).

For a number of reasons some experimental data were not or could not be used in the present work. In a previous study [24] it was found that none of the tested reaction mechanisms was able to describe the flame velocity data of [30], indicating that these measured values are somewhat contradictory to all other collected data. The $298 \mathrm{~K}$ series in [28] was disregarded, as it was obtained from extrapolating data measured at higher temperatures. As for RCM data, pressure profiles required to perform simulations could not be obtained from the authors [37], or just partially [40]. Some speciation data (e.g. one dataset in [44]) were inconsistent with other data.

A database for ethanol combustion was created from these experimental data, containing several thousand data points, which was used in the optimization and to compare the mechanism performances. Flame speciation data were also collected from literature, but not included here.

\section{The base mechanism and reactions to be optimized}

The mechanism of Saxena and Williams [48] was chosen based on its overall good performance in predict-

\footnotetext{
* Corresponding author: olm@caesar.elte.hu

Proceedings of the European Combustion Meeting 2015
} 
Table 1: Overview of the indirect measurements used in this work by the type of measurement and experimental facility. The numbers of included datasets and data points as well as the diluent systems are indicated (most frequently used diluent systems come first).

\begin{tabular}{lccl}
\hline $\begin{array}{l}\text { Type of measurement } \\
\text { experimental facility }\end{array}$ & $\begin{array}{c}\text { Data- } \\
\text { sets }\end{array}$ & $\begin{array}{c}\text { Data } \\
\text { points }\end{array}$ & Diluent systems \\
\hline Ignition delay times & $\mathbf{3 6}$ & $\mathbf{4 2 5}$ & $\begin{array}{l}\mathbf{A r}, \mathbf{N}_{2}, \mathbf{A r} / \mathbf{N}_{2}, \\
\mathbf{N e} / \mathbf{A r}\end{array}$ \\
Shock tube & 33 & 405 & $\mathrm{Ar}, \mathrm{N}_{2}, \mathrm{Ne} / \mathrm{Ar}$ \\
Rapid compression machine & 3 & 20 & $\mathrm{Ar} / \mathrm{N}_{2}$
\end{tabular}

$\begin{array}{lccl}\begin{array}{l}\text { Concentration } \\ \text { measurements* }\end{array} & \mathbf{4 7} & \mathbf{1 1 2 4 5} & \begin{array}{l}\mathbf{N e} / \mathbf{K r}, \mathbf{N}_{2}, \\ \mathbf{N e} / \mathbf{A r}, \mathbf{N}_{2} / \mathbf{H}_{2} \mathbf{O}\end{array} \\ \begin{array}{l}\text { Flow reactor concentration- } \\ \text { time profiles }\end{array} & 14 & 1322 & \mathrm{~N}_{2} \\ \begin{array}{l}\text { Flow reactor outlet concen- } \\ \text { trations** }\end{array} & 10 & 459 & \mathrm{~N}_{2} / \mathrm{H}_{2} \mathrm{O} \\ \begin{array}{l}\text { Jet-stirred reactor outlet } \\ \text { concentrations (JSR) }\end{array} & 9 & 593 & \mathrm{~N}_{2} \\ \begin{array}{l}\text { Shock tube concentration- } \\ \text { time profiles }\end{array} & 14 & 8871 & \mathrm{Ne} / \mathrm{Kr}, \mathrm{Ne} / \mathrm{Ar} \\ & & & \end{array}$

\begin{tabular}{lccl}
$\begin{array}{l}\text { Flame velocity } \\
\text { measurements }\end{array}$ & $\mathbf{1 1 7}$ & $\mathbf{9 3 7}$ & $\begin{array}{l}\mathbf{N}_{2}, \mathbf{N}_{2} / \mathbf{H}_{2} \mathbf{O}, \mathbf{A r}, \\
\mathbf{C O}_{2}, \mathbf{N}_{2} / \mathbf{A r}\end{array}$ \\
$\begin{array}{l}\text { Outwardly/ spherically } \\
\text { propagating flame }\end{array}$ & 70 & 479 & $\begin{array}{l}\mathrm{N}_{2}, \mathrm{~N}_{2} / \mathrm{H}_{2} \mathrm{O}, \\
\mathrm{N}_{2} / \mathrm{Ar}\end{array}$ \\
$\begin{array}{l}\text { Counterflow twin-flame } \\
\text { Heat flux method }\end{array}$ & 4 & 89 & $\begin{array}{l}\mathrm{N}_{2} \\
\mathrm{~N}_{2}, \mathrm{Ar}, \mathrm{CO}_{2}, \\
\mathrm{~N}_{2} / \mathrm{H}_{2} \mathrm{O}\end{array}$ \\
\hline
\end{tabular}

* Only major species considered here. These are: $\mathrm{C}_{2} \mathrm{H}_{5} \mathrm{OH}, \mathrm{O}_{2}, \mathrm{CO}$, $\mathrm{CO}_{2}, \mathrm{H}_{2}, \mathrm{H}_{2} \mathrm{O}, \mathrm{CH}_{4}, \mathrm{C}_{2} \mathrm{H}_{2}, m / z=28$ (i.e. a superposition of $\mathrm{CO}$ and $\mathrm{C}_{2} \mathrm{H}_{4}$ ) in [17] and $\mathrm{C}_{2} \mathrm{H}_{n}$ in [47]. Each species is internally counted as separate data point. Example: a measurement series (i.e. dataset) in which 10 species were recorded at 5 times/distances/temperatures has $10 \times 5=50$ data points

** Fuels used in the experiments: $\mathrm{C}_{2} \mathrm{H}_{2}+\mathrm{C}_{2} \mathrm{H}_{5} \mathrm{OH}$ : 288 data points/ 6 datasets, pure $\mathrm{C}_{2} \mathrm{H}_{5} \mathrm{OH}: 135 / 3$, pure $\mathrm{C}_{2} \mathrm{H}_{2}: 36 / 1$

ing the measured data. The $\mathrm{H}_{2} / \mathrm{CO}$ core of the original mechanism (reactions 1 to 30) was replaced by the optimized syngas mechanism developed in our earlier work [49]. Therefore, it was necessary to add the excited radical $\mathrm{OH}^{*}$ to the mechanism. Furthermore, the interaction of $\mathrm{OH}^{*}$ with $\mathrm{CH}_{4}$ was considered [50]. Noble gases $\mathrm{Kr}$ and $\mathrm{Ne}$ were added to the mechanism as they are used as bath gases in experimental studies.

Apart from the $\mathrm{H}_{2} / \mathrm{CO}$ core, only one more change was carried out in comparison to the original SaxenaWilliams-2007 mechanism: $\mathrm{CH}_{3} \mathrm{CHO}$ decomposition was defined as pressure-independent and only considering the dominant route to the products $\mathrm{CH}_{3}$ and $\mathrm{HCO}$ (reaction 147 in [48]). As in the recent work of Metcalfe et al. [51], we followed the suggestion of Sivaramakrishnan et al. [52] to assume pressure dependence and to add a second branch yielding $\mathrm{CH}_{4}$ and $\mathrm{CO}$ to the base mechanism.

As it will be shown in Table 3, the modification of the $\mathrm{H}_{2} / \mathrm{CO}$ chemistry and the structural change in the $\mathrm{CH}_{3} \mathrm{CHO}$ decomposition step already led to an improvement of the overall performance compared to the original mechanism, while there was a moderate increase in the size of the mechanism (49 species/251 reactions compared to $46 / 235$ in [48], if $\mathrm{NO}_{\mathrm{x}}$ chemistry is disregarded).
A brute-force first-order local sensitivity analysis at the conditions of the indirect experimental data was carried out using the base mechanism. For each simulated experimental data point, the sensitivities of the simulation result corresponding to a $5 \%$ change of the $A$-factors of each reaction step and (if applicable) to the third body efficiencies were calculated. The rate parameters of those reactions were selected for optimization that produced high sensitivity coefficient values at several experimental conditions. A list of the chosen rate parameters is given in Table 2. Altogether, 44 Arrhenius parameters of 14 reactions were selected. For reactions R176 and R177, both the high-pressure limit (HPL) and the low-pressure limit (LPL) Arrhenius parameters were optimized, for R68 only the LPL ones. For most selected reactions, all three Arrhenius parameters $(A, n, E)$ were optimized. In the case of reactions R60, R176 (LPL only) and R177, the two Arrhenius parameters $A$ and $E$ were sufficient to describe the temperature dependence of the rate coefficient. In two other cases, a three-parameter description was preferred over the temperature-independent (reaction R63) or the $(A, E)$-type parametrization (HPL of R176) suggested by Saxena and Williams [48].

If available from literature, direct measurements of the rate coefficients at conditions relevant in combustion were collected for the selected reactions and used as additional targets in the optimization. For $\mathrm{H}$ abstraction from $\mathrm{C}_{2} \mathrm{H}_{5} \mathrm{OH}$ by $\mathrm{OH}$ (reactions $\mathrm{R} 178$ to $\mathrm{R} 180$ in the base mechanism), data of [53-60] was used, in total 124 data points in 13 datasets within a temperature range of 295 1297 K. Direct rate coefficient measurements for the $\mathrm{C}_{2} \mathrm{H}_{5} \mathrm{OH}$ decomposition channels (R176, R177) were collected from [54, 61-64], in total 195 data points in 16 datasets within a range of $T=840-1899 \mathrm{~K}$. A single measured value of [65] at $T=423 \mathrm{~K}$ was used to delimit the rate coefficient of $\mathrm{C}_{2} \mathrm{H}_{5} \mathrm{OH}+\mathrm{CH}_{3}=\mathrm{CH}_{3} \mathrm{CHOH}+\mathrm{CH}_{4}$ (R188) at low temperatures. For the reaction $\mathrm{C}_{2} \mathrm{H}_{4}+\mathrm{OH}=$ $\mathrm{C}_{2} \mathrm{H}_{3}+\mathrm{H}_{2} \mathrm{O}$ (R104), 27 data points in 3 datasets were collected from [66-68], covering $T=651-1746 \mathrm{~K}$.

\section{The prior uncertainty domain of the parameters}

Global parameter optimization methods require the definition of a domain of uncertainty of the parameters, because the optimal parameter set is sought within this domain. The aim of the present optimization was to find physically realistic rate parameters. Therefore, the prior uncertainty domain of rate parameters had to be determined from direct measurements and theoretical calculations found in the literature. Articles that report the results of direct measurements provide the values of the measured rate coefficient of an elementary reaction at various temperatures, pressures and possibly using different bath gases.

The method for determining the prior uncertainty domain of the Arrhenius parameters has previously been described [69] for two elementary reactions and been applied to 22 reactions of the $\mathrm{H}_{2} / \mathrm{CO}$ system in [70]. For each elementary reaction investigated, all direct measurements and theoretical determinations of the rate coefficient were collected from the NIST Chemical Kinetics 
Database [71] and from review articles [36, 41, 48, 51, 72]. On an Arrhenius plot, the temperature dependence of $\ln k$ outlines an uncertainty band of the rate coefficient. The distance of the $k_{\min }$ and $k_{\max }$ limits from the centerline defines the temperature-dependent uncertainty parameter $f(T)$. The $f(T)$ points were converted to the prior covariance matrix of the Arrhenius parameters for each investigated reaction step $[69,73]$. This covariance matrix characterizes the joint posterior uncertainty domain of the parameters. Also, the width of the uncertainty band was used as the limiting value of the acceptable rate coefficients during the optimization. Reactions R68 and R104 could be treated this way and a normal probability distribution was assumed for these reactions. For all other reactions, very little literature information was available and constant $f$ values were estimated based on these scarce data and a uniform probability distribution had to be assumed. Values of $f(\mathrm{~T})$ for each optimized reaction can be found in Table 2 .

\section{Parameter optimization}

The global parameter optimization method applied here has been described in detail in [69]. Its use has been successfully demonstrated in [74-76]. The first round of optimization was carried out using response surfaces for all types of data except for concentration-time profiles. Starting from the parameter set obtained using these surrogate models, response surfaces were used in the second round of optimization for laminar flames only, which are computationally expensive if calculated directly. This two-step approach has been used successfully in [76].

The optimal set of parameters was obtained by the minimization of the following objective function:

$$
E(\mathbf{p})=\frac{1}{N} \sum_{\mathrm{i}=1}^{N} \frac{1}{N_{\mathrm{i}}} \sum_{\mathrm{j}=1}^{N_{i}}\left(\frac{Y_{\mathrm{ij}}^{\bmod }(\mathbf{p})-Y_{\mathrm{ij}}^{\exp }}{\sigma\left(Y_{\mathrm{ij}}^{\text {exp }}\right)}\right)^{2}
$$

Here $N$ is the number of datasets and $N_{\mathrm{i}}$ is the number of data points in the $i$ th dataset. The value $y_{\mathrm{ij}}^{\exp }$ is the $j$ th measured data point in the $i$ th dataset. For the indirect measurement data, the modeled value is $Y_{\mathrm{ij}}^{\bmod }$, obtained from a simulation using an appropriate detailed mechanism, which can be understood as a given set of rate parameters, p. For the direct measurements, $Y_{\mathrm{ij}}^{\bmod }$ corresponds to the calculated rate coefficient at a given temperature, pressure, and diluent composition. During the optimization, multiple parameter sets $\mathbf{p}$ are created, the corresponding $E(\mathbf{p})$ values are evaluated and the lowest value is accepted as the new optimum.

The standard deviation of an experiment was determined for each dataset separately, based on the scatter of the data and experimental uncertainties, if reported. Constant absolute error $\left(\sigma\left(y_{\mathrm{ij}}^{\mathrm{exp}}\right)\right.$ is identical for all $\left.j\right)$ was assumed for the measured flame velocities and species profiles, in this case $Y_{\mathrm{ij}}=y_{\mathrm{ij}}$ applies. Constant relative error $\left(\sigma\left(y_{\mathrm{ij}}^{\mathrm{exp}}\right)\right.$ is identical for all $j$ and thus $\left.Y_{\mathrm{ij}}=\ln y_{\mathrm{ij}}\right)$ was assumed for the ignition delay measurements and the rate coefficients determined in direct experiments.

The optimization involved the fitting of 44 parameters to several thousand data points which is a computationally challenging task, therefore a systematic hierarchical optimization strategy was devised. In the first optimization step those experimental data were selected as optimization targets that were sensitive only to the parameters of the lowest number of reactions (R116 and R104). Then more and more experimental data and the corresponding influential reactions were included following the same concept and all parameters considered up to that point were optimized. This resulted in the inclusion of further reactions in the following order: R179, R63, R176 (HPL), R196, R180, R177 (HPL), R190, R178, R176 (LPL), R182, R60, R68 (LPL), R188 and R177 (LPL).

Reaction $\mathrm{CH}_{3} \mathrm{CH}_{2} \mathrm{O}+\mathrm{M}=\mathrm{CH}_{3} \mathrm{CHO}+\mathrm{H}+\mathrm{M}(\mathrm{R} 195)$ was included in the first round of optimization, but the calculated posterior uncertainty domain was very large, indicating that the datasets do not contain enough information to describe this reaction quantitatively. Further somewhat important $\mathrm{C}_{1} / \mathrm{C}_{2}$ reactions include $\mathrm{CH}_{3}+\mathrm{O}_{2}=$ $\mathrm{CH}_{2} \mathrm{O}+\mathrm{OH}$ (R64), $\mathrm{C}_{2} \mathrm{H}_{3}+\mathrm{H}=\mathrm{C}_{2} \mathrm{H}_{2}+\mathrm{H}_{2}$ (R113), $\mathrm{C}_{2} \mathrm{H}_{5} \mathrm{OH}+\mathrm{HO}_{2}=\mathrm{CH}_{2} \mathrm{CH}_{2} \mathrm{OH}+\mathrm{H}_{2} \mathrm{O}_{2}$ (R191) and $\mathrm{CH}_{3} \mathrm{CHO}=\mathrm{CH}_{3}+\mathrm{HCO}$ (R162). However, the rate parameters of these reactions were only important at few conditions only and were not included in the present optimization.

\section{The optimized mechanism}

In the final optimization cycle, 400 shock tube ignition data points were used together with $18 \mathrm{RCM}$ data points, 762 flame velocity measurements, 1791 species concentration points from flow reactors, 569 jet-stirred reactor data points and 10785 points from shock tubes (including $\mathrm{CH}_{3} \mathrm{CHO}$ profile points) and 347 direct measurements. Table 2 presents the optimized values of the rate parameters compared to the original values in [48].

Table 3 shows that compared to the original SaxenaWilliams-2007 and the base mechanism, the overall value of the objective function decreased significantly as a result of the optimization. Also, the description of the experimental data improved for ignition delay times and concentration profiles, while it became slightly worse for measured flame velocities.

The covariance matrix of all optimized parameters was calculated as in $[69,76]$. The calculated posterior uncertainty limits can only be meaningful in a temperature range for which combustion data was included in the optimization, (approx. $750-2400 \mathrm{~K}$, i.e. $1000 \mathrm{~K} / T \approx 0.42$ 1.33). If at the extremes of this range, none of the experimental data is sensitive to a certain reactions, the information content of the respective uncertainty limits can be much lower, in other words, they can be much wider than the prior uncertainty limits. This behavior can be observed e.g. for R188 and R104 at high temperatures (see Fig. 1). For most other reactions, the uncertainties of $k$ could be effectively reduced in the whole temperature 
Table 2. Reactions selected for optimization, the rate parameters in the base mechanism (taken from [48]) and the optimized values of the parameters. Units are in $\mathrm{cm}, \mathrm{mol}, \mathrm{K}$ and $\mathrm{s}$. Values of the prior and posterior uncertainty parameters are given for the temperature range of 500-2500 K.

\begin{tabular}{|c|c|c|c|c|c|c|c|c|c|}
\hline No. & Reaction string & $f_{\text {prior }}$ & $f_{\text {posterior }}$ & $A_{\text {orig }}$ & $n_{\text {orig }}$ & $E_{\text {orig }}$ & $A_{\text {opt }}$ & $n_{\text {opt }}$ & $E_{\text {opt }}$ \\
\hline R60 & $\mathrm{H}_{3}+\mathrm{OH}=\mathrm{CH}_{2}(\mathrm{~S})+\mathrm{H}_{2} \mathrm{O}$ & 1.0 & $0.67-0.95$ & $4.000 \mathrm{E}+13$ & - & 1259.38 & $4.466 \mathrm{E}+12$ & - & 981.62 \\
\hline R63 & $\mathrm{H}_{3}+\mathrm{HO}_{2}=\mathrm{CH}_{3} \mathrm{O}+\mathrm{OH}$ & 1.0 & $53-1.04$ & $5.000 \mathrm{E}+12$ & - & 0 & $4.878 \mathrm{E}+03$ & 2.276 & -2771.60 \\
\hline R68 LPL & $\mathrm{H}+\mathrm{CH}_{3}+\mathrm{M}=\mathrm{CH}_{4}+\mathrm{M}$ & $0.70-1.06$ & $0.22-0.54$ & $2.470 \mathrm{E}+33$ & -4.760 & 1227.98 & $1.503 \mathrm{E}+31$ & -4.121 & -240.91 \\
\hline R104 & $\mathrm{C}_{2} \mathrm{H}_{4}+\mathrm{OH}=\mathrm{C}_{2} \mathrm{H}_{3}+\mathrm{H}_{2} \mathrm{O}$ & $.32-0.73$ & $18-0.80$ & $5.530 \mathrm{E}+05$ & 2.310 & 1491.53 & $4.770 \mathrm{E}+05$ & 2.232 & 1198.33 \\
\hline R116 & $\mathrm{C}_{2} \mathrm{H}_{3}+\mathrm{O}_{2}=\mathrm{CH}_{2} \mathrm{CHO}+\mathrm{O}$ & 0.4 & $0-0.76$ & $7.000 \mathrm{E}+14$ & -0.611 & 2648.43 & $4.703 \mathrm{E}+03$ & 2.677 & 340.73 \\
\hline R176 HPL & $\mathrm{C}_{2} \mathrm{H}_{5} \mathrm{OH}=\mathrm{CH}_{3}+\mathrm{CH}_{2} \mathrm{OH}$ & 1.0 & $0.52-0.72$ & $5.000 \mathrm{E}+15$ & - & 41268.25 & $2.993 E+29$ & -4.248 & 43149.57 \\
\hline R176 LPL & $\mathrm{C}_{2} \mathrm{H}_{5} \mathrm{OH}+\mathrm{M}=\mathrm{CH}_{3}+\mathrm{CH}_{2} \mathrm{OH}+\mathrm{M}$ & 1.0 & $.50-0.66$ & $3.000 \mathrm{E}+16$ & - & 29189 & $3.012 \mathrm{E}+17$ & - & 29215.00 \\
\hline R177 HPL & $\mathrm{C}_{2} \mathrm{H}_{5} \mathrm{OH}=\mathrm{C}_{2} \mathrm{H}_{4}+\mathrm{H}_{2} \mathrm{O}$ & 1.0 & & $8.000 \mathrm{E}+13$ & - & 32712.63 & $3.773 \mathrm{E}+13$ & - & 33215.34 \\
\hline R177 LPL & $\mathrm{C}_{2} \mathrm{H}$ & 1.0 & .56 & $1.000 \mathrm{E}+17$ & - & 27176.65 & $9.951 \mathrm{E}+17$ & - & 27191.22 \\
\hline $\mathrm{R} 178$ & & 1.0 & & $1.810 \mathrm{E}+11$ & 0.400 & 360.85 & $1.468 \mathrm{E}+26$ & -4.138 & 3163.38 \\
\hline R179 & & 1.0 & 1.07 & $3.090 \mathrm{E}+10$ & 0.500 & -191.24 & $7.247 \mathrm{E}+11$ & -0.060 & -296.39 \\
\hline R180 & & 1.0 & & $1.050 \mathrm{E}+10$ & 0.800 & 360.85 & $8.981 \mathrm{E}+03$ & 2.867 & 185.05 \\
\hline R182 & $\mathrm{C}_{2} \mathrm{H}_{5} \mathrm{OH}+\mathrm{H}=\mathrm{CH}_{3} \mathrm{CHOH}+\mathrm{H}_{2}$ & 1.0 & $0.32-0.65$ & $2.580 \mathrm{E}+07$ & 1.600 & 1424.26 & $6.928 \mathrm{E}+25$ & -3.837 & 4938.97 \\
\hline R188 & $\mathrm{C}_{2} \mathrm{H}_{5} \mathrm{OH}+\mathrm{CH}_{3}=\mathrm{CH}_{3} \mathrm{CHOH}+\mathrm{CH}_{4}$ & 0.4 & $.35-0.70$ & $7.280 \mathrm{E}+02$ & 3.000 & 4001.01 & $1.103 \mathrm{E}+08$ & 1.540 & 5370.84 \\
\hline R190 & $\mathrm{C}_{2} \mathrm{H}_{5} \mathrm{OH}+\mathrm{HO}_{2}=\mathrm{CH}_{3} \mathrm{CHOH}+\mathrm{H}_{2} \mathrm{O}_{2}$ & 1.0 & $0.07-0.85$ & $8.200 \mathrm{E}+03$ & 2.500 & 5435.33 & $2.689 \mathrm{E}+27$ & -4.343 & 10516.47 \\
\hline R196 LPL & $\mathrm{CH}_{3} \mathrm{CH}_{2} \mathrm{O}+\mathrm{M}=\mathrm{CH}_{3}+\mathrm{CH}_{2} \mathrm{O}+\mathrm{M}$ & 0.7 & $0.8-0.92$ & $5.350 \mathrm{E}+37$ & -7.000 & 11977.86 & $4.001 \mathrm{E}+30$ & -5.070 & 10429.13 \\
\hline
\end{tabular}

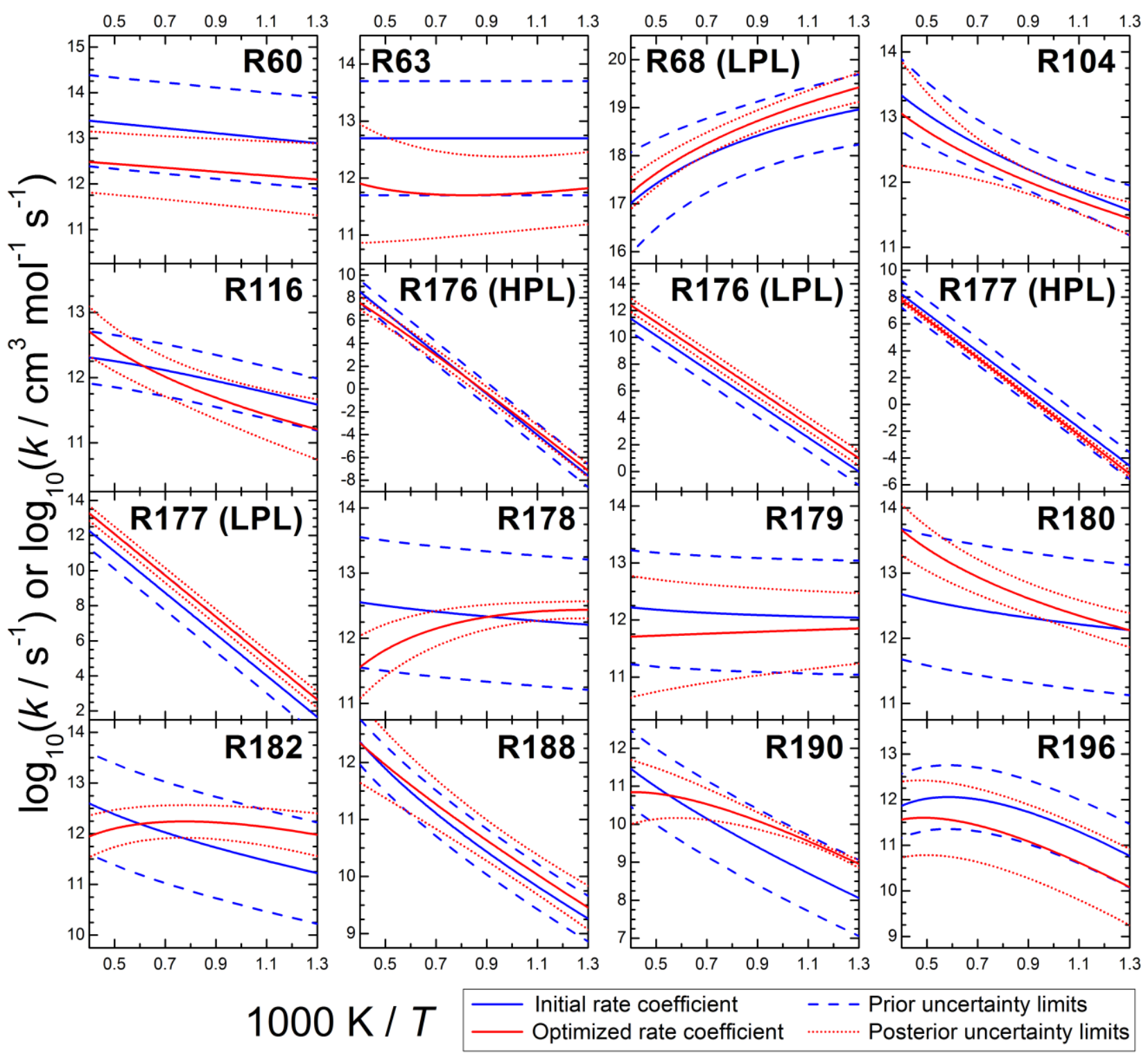

Fig. 1. Arrhenius plots of the initial and optimized rate coefficients with their prior and posterior uncertainty ranges for the 16 optimized reactions. Rate coefficient units are $\mathrm{s}^{-1}$ for the high-pressure limits (HPL) of reactions R176 and $\mathrm{R} 177$, and $\mathrm{cm}^{3} \mathrm{~mol}^{-1} \mathrm{~s}^{-1}$ for the other reactions. 
Table 3. Comparison of error function values by experiment type and overall between 13 recently published mechanisms, the base mechanism for optimization (see text) and the new optimized mechanism. The corresponding number of data points and datasets for each column are denoted below the double solid line. Solvers of the CHEMKIN-II package (CK) were used. For premixed flames, simulations were also performed with OpenSMOKE (OS).

\begin{tabular}{|c|c|c|c|c|c|c|}
\hline \multirow{2}{*}{ Mechanism ID } & \multirow{2}{*}{$\begin{array}{c}\text { Ignition delay times } \\
\text { CK }\end{array}$} & \multicolumn{2}{|c|}{ Flame velocities } & \multirow{2}{*}{$\begin{array}{c}\text { Major species profiles* } \\
\text { CK }\end{array}$} & \multicolumn{2}{|c|}{ Overall } \\
\hline & & $\mathrm{CK}$ & OS & & CK only & OS for flames \\
\hline Kathrotia-2011** & 185.7 & - & 160.5 & 357.2 & - & 211.2 \\
\hline Konnov-2009 & 92.6 & - & - & 1179.9 & - & - \\
\hline Leplat-2010 & 66.5 & 10.6 & 10.5 & 116.2 & 45.5 & 45.4 \\
\hline Marinov-1999 & 92.0 & - & 26.3 & 109.2 & - & 57.6 \\
\hline RDmech-2009 & 85.6 & 41.8 & 21.9 & 1272.5 & 338.9 & 327.3 \\
\hline RöhlPeters-2009 & 90.7 & 13.2 & 21.0 & 96.0 & 46.6 & 51.2 \\
\hline SanDiego-2014 & 32.4 & 61.0 & 38.6 & 5019.8 & 1221.2 & 1208.1 \\
\hline SaxenaWilliams-2007 & 83.7 & 22.6 & 11.9 & 248.7 & 86.7 & 80.5 \\
\hline Zaragoza-2011 & 65.1 & - & - & 133.1 & - & - \\
\hline DagautTogbé-2012** & 72.8 & - & 250.7 & 89.7 & - & 180.9 \\
\hline Ogura-2007 & 98.2 & - & - & 105.3 & - & - \\
\hline UCL44f-2013 & 76.6 & - & - & 215.4 & - & - \\
\hline ZhongZheng-2013*** & 82.9 & 10.9 & 11.4 & 915.4 & 236.4 & 236.7 \\
\hline Base mechanism & 68.5 & 14.9 & 11.2 & 144.4 & 55.0 & 52.8 \\
\hline New optimized mechanism & $18.1\left(1^{\mathrm{st}}\right)$ & $20.8\left(4^{\text {th }}\right)$ & $26.3\left(6^{\text {th }}\right)$ & $65.3\left(1^{\mathrm{st}}\right)$ & $30.8\left(1^{\mathrm{st}}\right)$ & $34.0\left(1^{\mathrm{st}}\right)$ \\
\hline No. of data points & 36 & & & 47 & & 200 \\
\hline No. of datasets & 425 & & & 11245 & & 12607 \\
\hline \multicolumn{7}{|c|}{$\begin{array}{l}\left.\text { Major species are: } \mathrm{C}_{2} \mathrm{H}_{5} \mathrm{OH}, \mathrm{O}_{2}, \mathrm{CO}, \mathrm{CO}_{2}, \mathrm{H}_{2}, \mathrm{H}_{2} \mathrm{O}, \mathrm{CH}_{4}, \mathrm{C}_{2} \mathrm{H}_{2}, m / z=28 \text { (i.e. a superposition of } \mathrm{CO} \text { and } \mathrm{C}_{2} \mathrm{H}_{4}\right) \text { in [17] and } \mathrm{C}_{2} \mathrm{H}_{\mathrm{n}} \text { in [47]. } \\
\text { For flame simulations, all species with } \geq 4 \mathrm{C} \text { atoms were removed from the mechanisms, together with all reactions in which they participate. } \\
\text { In shock tube simulations, } \mathrm{d} p / \mathrm{d} t \text { was chosen as an ignition criterion wherever necessary, as the } \mathrm{CH} \text { radical is not defined in the mechanism. } \\
\text { For flame simulations, all species with } \geq 6 \mathrm{C} \text { atoms were removed from the mechanisms, together with all reactions in which they participate. } \\
\text { Some simulation results are not (yet) available. Overall results were not generated. }\end{array}$} \\
\hline
\end{tabular}

range of interest as a result of optimization. The obtained branching ratios of $\mathrm{H}$ abstraction from $\mathrm{C}_{2} \mathrm{H}_{5} \mathrm{OH}$ by $\mathrm{OH}$ at $900 \mathrm{~K}\left(k_{\alpha} / k_{\text {sum }}=k_{\mathrm{R} 179} / k_{\text {sum }}=48 \%, k_{\beta} / k_{\text {sum }}=k_{\mathrm{R} 178} / k_{\text {sum }}=\right.$ $12 \%, k_{\mathrm{OH}} / k_{\mathrm{sum}}=k_{\mathrm{R} 180} / k_{\mathrm{sum}}=40 \%$ ) are considerably different from most of the branching ratios found in the review article of Sarathy et al. [77], but are similar to the recently obtained data of [59] regarding the importance of abstraction from the $\mathrm{OH}$ site. The issue of branching ratios requires further attention in future optimizations.

\section{Comparison to published ethanol mechanisms}

In recent years, detailed ethanol combustion mechanisms were published by Kathrotia [78] (63 species/420 reactions, with $\mathrm{NO}_{\mathrm{x}}$ chemistry), Konnov [79] (129/1231, developed for $\mathrm{C}_{2} / \mathrm{C}_{3}$ hydrocarbons and oxygenates), Leplat et al. [41] (60/397), Marinov [72] (57/383), Herzler and Naumann [80] (64/399, "RD mech"), the San Diego group [81] (50/244, optionally with $\left.\mathrm{NO}_{\mathrm{x}}\right)$, Saxena and Williams [48] (59/288, with $\left.\mathrm{NO}_{\mathrm{x}}\right)$ and the Zaragoza group [82] (79/536, with $\left.\mathrm{NO}_{\mathrm{x}}\right)$. Röhl and Peters [83] published a reduced, but still comparatively comprehensive ethanol mechanism (38/228). Ethanol mechanisms employing the PLOG formalism to describe pressure dependence were published by Metcalfe et al. [51] and the NTUA group [84]. Unfortunately, these could not be used in the present paper since PLOG is not implemented in the original CHEMKIN-II solvers. Larger mechanisms also tested against ethanol data and used for comparison in the present work were published by the UCL group [85] (benzene), Dagaut and Togbé [86], Ogura et al. [87] and Zhong and Zheng [88] (all iso-octane).

Inert species $\mathrm{Kr}$ and $\mathrm{Ne}$ were added to all mechanisms, assuming unit third body collision efficiencies for all low-pressure reactions. Similarly, Ar was added to the Marinov-1999 and RöhlPeters-2009 mechanisms.

While only ranked $4^{\text {th }}$ (based on CHEMKIN-IIresults) for flame velocities among the investigated mechanisms, the major strength of the newly optimized mechanism is its improved accuracy in 0D simulations. Ignition delay times and especially concentration profiles are - on average - predicted more accurately. Consequently, it is the overall best mechanism in the present comparison.

Mechanisms such as Leplat-2010 and ZhongZheng2013 are (on average) relatively insensitive towards the choice of flame solver. Other mechanisms - including the new optimized mechanism - show largely differing average $E$ values for the CHEMKIN-II (CK) and OpenSMOKE (OS) simulations. This corresponds to differences in the simulation results that can be as large as $\left(S_{\mathrm{L}, \mathrm{CK}}-S_{\mathrm{L}, \mathrm{OS}}\right)=-2 \ldots+7 \mathrm{~cm} / \mathrm{s}$ depending on the mechanism, which requires further analysis.

\section{Conclusions}

An optimization of a detailed ethanol combustion mechanism starting from the one of Saxena and Williams [48] is demonstrated in the present article. A large amount of experimental data was collected from the literature including ignition delay time, flame velocity, and concentration profile measurements and direct measurements of rate coefficients. As a results of local sensitivity analysis, 44 Arrhenius parameters of 14 elementary reactions were identified which were optimized. All available direct measurements and theoretical determinations related to these reactions were used to outline the prior uncertainty domain of the rate coefficients. The optimization provided optimized values for all parameters as well as posterior uncertainty bands for the rate coefficients. 
The performance of the optimized mechanism was compared with those of several published mechanisms. It was shown that the optimized mechanism clearly provides the overall best description of the currently available experimental data, while the optimized rate coefficients are consistent with the respective direct measurements and literature values.

The complete optimized mechanism in CHEMKIN format is available on request from the authors.

\section{Acknowledgements}

The authors acknowledge the support of the Hungarian Scientific Research Fund OTKA (ERA Chemistry grant NN100523), of the Saxon Ministry of Science and Fine Arts and the EU in the project 100097882 ,BioRedKat" as well as of the Federal Ministry of Food and Agriculture in the project 22008613 "Entwicklung von chemischen Mechanismen zur energetischen Nutzung von Biokraftstoffen". The helpful discussions with Professor Henry J. Curran are greatly acknowledged. Carsten Olm thanks the Balassi Intézet/ HSB for their financial support.

\section{References}

1. R. F. A. (RFA), Falling Walls \& Rising Tides - 2014 Ethanol Industry Outlook. (2014).

2. D. Bradley, et al., Combust. Flame 156 (2009) 1462-1470.

3. E. Varea, et al., Combust. Flame 159 (2012) 577-590.

4. S. Y. Liao, et al., Appl. Therm. Eng. 27 (2007) 374-380.

5. T. Hara; K. Tanoue, FISITA 2006 World Automotive Congress,

Yokohama, Japan (2006) Technical Report F2006SC40.

6. J. T. Farrell, et al., SAE Paper (2004) 2004-01-2936.

7. G. Broustail, et al., Fuel 90 (2011) 1-6.

8. G. Broustail, et al., Fuel 106 (2013) 310-317.

9. K. Ohara, et al., J. Japan Inst. Energy 89 (2010) 1088-1094.

10. S. Jerzembeck. Dissertation, Rheinisch-Westfälische Technische Hochschule Aachen, 2010.

11. E. Varea, et al., Proc. Combust. Inst. 34 (2013) 735-744.

12. J. Beeckmann, et al., Proc. 6th Europ. Combust. Meeting (2013) Paper P3-76.

13. J. Beeckmann, et al., SAE Paper (2009) 2009-01-2784.

14. Ö. L. Gülder, Proc. Combust. Inst. 19 (1982) 275-281.

15. J. Beeckmann, et al., Fuel 117 (2014) 340-350.

16. N. Hinton; R. Stone, $23^{\text {rd }}$ Journées d'Étude of the Belgian Section of the Combustion Institute (2014).

17. M. Aghsaee, et al., Proc. Combust. Inst. 35 (2015) 393-400.

18. J. Liang, et al., Energ. Fuel 28 (2014) 4754-4761.

19. A. A. Konnov, et al., Proc. Combust. Inst. 33 (2011) 1011-1019.

20. J. P. J. van Lipzig, et al., Fuel 90 (2011) 2773-2781.

21. P. A. Glaude, et al., Proc. 5th Europ. Combust. Meeting (2011)

Paper 268 .

22. F. Rau, et al., Proc. Combust. Inst. 6 (2013) Paper P4-77.

23. J. D. Nauclér, Personal communication (2014).

24. C. Olm, J. D. Nauclér, A. A. Konnov, S. Hartl, C. Hasse, F. Rau,

T. Turányi, 35th International Symposium on Combustion (2014)

WiP Poster W3P040.

25. L. Sileghem, et al., Fuel 115 (2014) 32-40.

26. P. Dirrenberger, et al., Fuel 115 (2014) 162-169.

27. S. Voss, et al., Proc. 7th Europ. Combust. Meeting (2015) P3-46.

28. F. N. Egolfopoulos, et al., Proc. Combust. Inst. 24 (1992) 833

841.

29. P. S. Veloo, et al., Combust. Flame 157 (2010) 1989-2004.

30. C.-H. Wang; W.-B. Wang, J. Chin. Soc. Mech. Eng. 18 (1997)

75-83.

31. K. E. Noorani, et al., Energ. Fuel 24 (2010) 5834-5843.

32. D. F. Cooke, et al., Combust. Flame 16 (1971) 233-236.

33. F. Gillespie; H. J. Curran, Personal communication (2013)

34. J. Herzler; C. Naumann, Proc. 6th Europ. Combust. Meeting (2013) Paper P3-8
35. K. Natarajan; K. A. Bhaskaran, $13^{\text {th }}$ Intern. Symp. Shock Waves (1982) 834-842

36. L. R. Cancino, et al., Energ. Fuel 24 (2010) 2830-2840.

37. C. Lee, et al., Z. Phys. Chem. 226 (2012) 1-27.

38. K. A. Heufer; H. Olivier, Shock Waves 20 (2010) 307-316

39. K. A. Heufer, et al., Proc. 5th Europ. Combust. Meeting (2011)

Paper 281.

40. G. Mittal, et al., Combust. Flame 161 (2014) 1164-1171.

41. N. Leplat, et al., Combust. Flame 158 (2011) 705-725.

42. P. Dagaut, et al., J. Chim. Phys. 89 (1992) 867-884.

43. T. S. Norton; F. L. Dryer, Int. J. Chem. Kinet. 24 (1992) 319-344.

44. J. Li, et al., $5^{\text {th }}$ US Combustion Meeting (2007) Paper \# C26.

45. M. U. Alzueta; J. M. Hernández, Energ. Fuel 16 (2002) 166-171.

46. M. Abián, et al., Energ. Fuel 22 (2008) 3814-3823.

47. J. Kiecherer, et al., Proc. Combust. Inst. 35 (2015) 465-472.

48. P. Saxena; F. A. Williams, Proc. Combust. Inst. 31 (2007) 1149-

1156 .

49. T. Varga, C. Olm, I. Gy. Zsély, É. Valkó, H. J. Curran, T. Turányi, 35th International Symposium on Combustion (2014) WiP Poster W3P093.

50. A. Kéromnès, et al., Combust. Flame 160 (2013) 995-1011.

51. W. K. Metcalfe, et al., Int. J. Chem. Kinet. 45 (2013) 638-675.

52. R. Sivaramakrishnan, et al., J. Phys. Chem. A 114 (2010) 755

764.

53. J. F. Bott; N. Cohen, Int. J. Chem. Kinet. 23 (1991) 1075-1094.

54. R. Sivaramakrishnan, et al., J. Phys. Chem. A 114 (2010) 9425-

9439.

55. U. Meier, et al., Chem. Phys. Lett. 115 (1985) 221-225.

56. U. Meier, et al., Chem. Phys. Lett. 133 (1987) 162-164.

57. W. P. Hess; P. Tully, Chem. Phys. Lett. 152 (1988) 183-189.

58. K. Lorenz, et al., Personal communication (1984).

59. S. A. Carr, et al., J. Phys. Chem. A 115 (2011) 3335-3345.

60. I. Stranic, et al., J. Phys. Chem. A 118 (2014) 822-828.

61. J. Herzler, et al., J. Phys. Chem. A 1001 (1997).

62. J. Park, et al., J. Chem. Phys. 117 (2002) 3224-3231.

63. J. Li, et al., J. Phys. Chem. A 108 (2004) 7671-7680

64. C.-W. Wu, et al., J. Phys. Chem. A 115 (2011) 8086-8092.

65. K. M. Bansal; G. R. Freeman, J. Am. Chem. Soc. 90 (1968) $7183-$

7189.

66. F. P. Tully, Chem. Phys. Lett. 143 (1988) 510-514

67. A. Bhargava; P. R. Westmoreland, Combust. Flame 113 (1998)

333-347.

68. A.-D. Liu, et al., Int. J. Chem. Kinet. 19 (1987) 25-34.

69. T. Turányi, et al., Int. J. Chem. Kinet. 44 (2012) 284-302.

70. T. Nagy, et al., Combust. Flame (2015) in press, DOI:

10.1016/j.combustflame.2015.01.005.

71. J. A. Manion, et al. NIST Chemical Kinetics Database, NIST

Standard Reference Database 17, Version 7.0 (Web Version), Release

1.6.8, Data version 2013.03, National Institute of Standards and

Technology, Gaithersburg, Maryland, 20899-8320. http://kinetics.nist.gov/.

72. N. M. Marinov, Int. J. Chem. Kinet. 31 (1999) 183-220.

73. T. Nagy; T. Turányi, Int. J. Chem. Kinet. 43 (2011) 359-378

74. I. G. Zsély, et al., Energy 43 (2012) 85-93.

75. T. Varga, et al., Int. J. Chem. Kinet. 46 (2014) 295-304.

76. T. Varga, et al., Proc. Combust. Inst. 35 (2015) 589-596.

77. S. M. Sarathy, et al., Prog. Energy Combust. Sci. 44 (2014) 40 102.

78. T. Kathrotia. Dissertation, Karls-Universität Heidelberg, 2011.

79. A. A. Konnov, Combust. Flame 156 (2009) 2093-2105.

80. J. Herzler; C. Naumann, Proc. Combust. Inst. 32 (2009) 213-220.

81. Mechanical and Aerospace Engineering (Combustion Research),

University of California at San Diego: Chemical-Kinetic Mechanisms

for Combustion Applications, San Diego Mechanism, version 2014-

10-04 (http://combustion.ucsd.edu).

82. C. Esarte, et al., Ind. Eng. Chem. Res. 50 (2011) 4412-4419.

83. O. Röhl; N. Peters, Proc. 4th Europ. Combust. Meeting (2009) Paper 810336.

84. G. Vourliotakis, et al., Proc. Combust. Inst. 35 (2015) 437-445.

85. V. Dias, et al., Combust. Flame 161 (2014) 2297-2304.

86. P. Dagaut; C. Togbé, Combust. Sci. Technol. 184 (2012) 1025

1038.

87. T. Ogura, et al., Energ. Fuel 21 (2007) 3233-3239.

88. B.-J. Zhong; D. Zheng, Combust. Sci. Technol. 185 (2013) $627-$ 644. 